\title{
MEDIDAS CAUTELARES Y NUEVAS FUNCIONES DEL JUEZ EN LA FORMULAGIÓN DE POLÍTICAS PÚBLICAS*
}

\author{
JUDICIAL INJUNCTIONS AND THE NEW ROLE OF JUDGES \\ IN THE FORMULATION OF PUBLIC POLICIES
}

\author{
Valentín THuRY CORNEJO**
}

\begin{abstract}
RESUMEN: Las transformaciones sociales, culturales y políticas han puesto en discusión la legitimidad del actuar estatal, y ello repercute en instituciones tradicionales del derecho administrativo, como la presunción de legitimidad y la ejecutoriedad del acto administrativo. Crecientemente, los ciudadanos y las organizaciones de la sociedad civil concurren ante los jueces en resguardo de los derechos humanos que las Constituciones y normas les reconocen. Los jueces, llamados a mediar entre un interés general configurado en instancia administrativa y unos derechos individuales reconocidos en las Constituciones que ellos deben interpretar, intervienen en la esfera administrativa, y lo hacen, en un primer momento, a través de medidas cautelares que frenan ese proceso administrativo. En este artículo explicamos la actual importancia de las medidas cautelares como el producto de dos
\end{abstract}

ABSTRACT: Social, cultural, and political transformations generated a discussion around the legitimacy of public policies. Administrative law principles such as the presumption of legitimacy and the capacity of Administration to execute its own decisions are now being discussed. Increasingly, citizens and NGOs go to the courts to seek protection for the rights written in bills and Constitutions. Fudges must mediate between the public interest as defined by government and individual rights that they must interpret. They do so by intervening in the administrative sphere, using judicial injunctions that stop the decisional and implementation process. In this article we explain the current relevance of those injunctions as the result of two structural trends: judicialization and emergency. Both processes are deeply interrelated and thought the enactment of injunctions, courts change substantially the way in which they participate in the formation of public policies. Its control ceases to be ex post and begins to be part of the very same process of policy formation.

* Artículo recibido el 4 de diciembre de 2015 y aceptado para su publicación el 8 de junio de 2016.

** Investigador independiente del Consejo Nacional de Investigaciones Científicas y Técnicas de Argentina (Conicet); director del Programa en Desarrollo, Innovación y Sociedad de FLACSO Argentina, y profesor del máster en magistratura judicial de la Universidad Austral.

Es doctor en derecho por la Universidad Carlos III de Madrid; máster en Communication Studies por la Universidad de Texas en Austin, y máster en derecho administrativo por la Universidad Austral (Buenos Aires). Asimismo, ha realizado la diplomatura en estudios políticos y constitucionales en el Centro de Estudios Políticos y Constitucionales de Madrid. 
fenómenos estructurales que confluyen: la judicialización y la emergencia. Ambos procesos se encuentran mutuamente imbricados, y es a través de los procesos cautelares como los jueces cambian sustancialmente su participación en el proceso de toma de decisiones públicas, dejando de ser un control ex post para pasar a ser parte de la misma secuencia decisoria de la política pública.

Palabras clave: Medidas cautelares, judicialización, emergencia, políticas públicas.

Keyzerords: Fudicial injunctions, judicialization, emergency, public policies.

SUMARIO: I. Introducción. II. Judicialización, juridificación, constitucionalización. III. La posición del juez. IV. Modos de intervención judicial. V. Legitimidad social del juez. VI. Epílogo. VII. Bibliografia.

\section{INTRODUCCIÓN}

El sistema de gobierno democrático ha sufrido numerosas transformaciones en las últimas décadas, producidas en el marco de cambios sociales, culturales y políticos, que han puesto en discusión la legitimidad del actuar estatal. El auge de nuevas formas y modalidades de protesta social ${ }^{1}$ dan cuenta de esta situación en la que, al decir de Karl Marx, "todo lo sólido se desvanece en el aire". ${ }^{2}$ El actuar administrativo sufre una merma en su prestigio y en sus acciones, antes encarnaciones del interés público, son ahora discutidas enarbolando las cartas de los derechos humanos que los particulares y grupos revisten frente a ellas. Los encargados de resolver estos conflictos son, generalmente, los jueces, que están llamados así a mediar entre un interés general configurado en instancia administrativa y unos derechos individuales reconocidos en las Constituciones que ellos deben interpretar. La crisis de legitimidad tiende un manto de duda sobre el accionar administrativo, muchas veces oscuro y poco transparente, y los nuevos actores en el proceso político ven en los jueces un interlocutor donde hacer

1 Asociación por los Derechos Civiles (ADC), "Vamos a portarnos mal". Protesta socialy Libertad de Expresión en América Latina, Buenos Aires, ADC-Friedich Ebert Stiftung, 2011.

2 Berman, Marshall, Todo lo sólido se desvanece en el aire. La experiencia de la modernidad, Madrid, Siglo XXI Editores, 1988. 
oír su voz. Éstos, amparados en una lectura expansiva de los derechos humanos, encuentran legitimidad para intervenir en la esfera administrativa y lo hacen a través de instrumentos de intervención muchas veces sumarios: las medidas cautelares. Surge así un nuevo modelo de formación de las decisiones públicas, pendiente todavía de teorización y concreción normativa, que corroe los fundamentos sobre los que tradicionalmente se asentó el derecho administrativo continental europeo, fuente de la mayor parte de los ordenamientos latinoamericanos. La interpretación y ejecución del "bien común"3 no puede ya presumirse en cabeza de la administración de un modo unificado, sino que su determinación se complejiza con otros actores y visiones intervinientes. La pregunta a formular sería así: ¿estamos ante un nuevo paradigma?

La respuesta no resulta sencilla, ya que el fenómeno es complejo y se encuentra en plena evolución. Pero sí podemos intentar, al menos, analizar la permanencia de los cambios que estamos experimentando y dilucidar si los mismos resultan fenómenos pasajeros o son configuraciones de un nuevo estado de cosas - aun cuando todavía no veamos sus contornos perfectamente definidos-. Sin pretensiones de exhaustividad, intentaremos en las páginas que siguen, explicar la creciente importancia que asumen las medidas cautelares dictadas por los jueces en el proceso administrativo como el producto de dos fenómenos estructurales que confluyen. El primero es el de judicialización, entendiendo por esto un mayor ámbito decisional en manos de los jueces, así como su mayor intervención en la definición e implementación de los asuntos públicos. Esta dinámica posee múltiples aristas, que van desde cambios en la constitución misma del derecho a transformaciones producidas en el sistema político, y que producen ese resultado. La judicialización se lee como una modificación de los marcos normativos y cognitivos tradicionales del constitucionalismo, en los cuales el juez se limitaba a la aplicación del derecho, siendo un mero "instrumento que pronuncia las palabras de la ley, seres inanimados que no pueden moderar ni la fuerza ni el rigor de las leyes". ${ }^{4} \mathrm{El}$ segundo fenómeno al que nos referimos es el de la emergencia y consolidación de procesos urgentes de resolución de conflictos, sean éstos de carácter

3 Barra, Rodolfo Carlos, Principios de derecho administrativo, Buenos Aires, Ediciones Ábaco, 1980.

4 Montesquieu, Barón de, Del espiritu de las leyes, 2a. ed., trad. de Mercedes Blázquez y Pedro de Vega, Madrid, Tecnos, 1993, p. 112. 
autónomo o accesorio de procesos principales. Una lectura apresurada del proceso podría sugerirnos una relación de género-especie en estos cambios estructurales: los jueces intervienen más - judicialización-, y uno de los modos en que lo hacen es a través de procesos abreviados - cautelarización- En nuestra opinión, en cambio, ambas características están estructuralmente imbricadas: los jueces intervienen más, y un modo en que esa intervención es cualitativamente mayor es cuando se hace a través de procesos cautelares, ya que esta modalidad cambia sustancialmente su participación en el proceso de toma de decisiones públicas, dejando de ser un control ex post para pasar a ser parte de la misma secuencia decisoria de la política pública.

El hilo conductor de este artículo está dado por el concepto de legitimidad, entendida ésta en un sentido que supera la mera competencia legalmente establecida, y se extiende a su sentido cultural, social y político. Ello es, investigar el corrimiento del eje decisorio de la administración a los jueces - $\mathrm{O}$, al menos, su mayor intervención - supone descorrer el velo sobre una serie de procesos sociales, políticos y jurídicos que afectan la estructura misma del sistema institucional de las democracias contemporáneas. De este modo, es necesario comprender el vínculo que se produce entre la sociedad y el Poder Judicial, como lugar donde los derechos humanos - que emergen como la piedra angular del sistema- van a ser reconocidos. Es la legitimidad que adquieren en virtud de esa relación la que va a permitir que los jueces - dotados de una legitimidad indirectacomiencen a intervenir en procesos liderados por instancias con legitimidad democrática directa, como son los ejecutivos elegidos por voto popular. ${ }^{5}$ De dónde proviene, pues, la legitimidad judicial y qué implicancia tiene para los poderes de la administración pública en la consecución de sus objetivos de interés público? Responder a esta pregunta supone analizar las instituciones del derecho administrativo desde una perspectiva que trascienda lo meramente legal, y así explique la relativización que sufren principios tradicionales, como el de la ejecutoriedad del acto administrativo. Al hacerlo de este modo, la emergencia de las acciones cautelares contra la administración pública adquiere el carácter de puerta de entrada

5 Estas afirmaciones de carácter general deberían ser moduladas en los distintos países, de acuerdo con sus variables propias. Aquí las realizamos con pretensión abarcativa, pero sobre el telón de fondo de la realidad argentina. 
a procesos más amplios y generales que los que una formulación inicial como meras excepciones a la ejecutoriedad de la decisión administrativa supondría.

\section{JUDICIALIZACIÓN, JURIDIFICACIÓN, CONSTITUGIONALIZAGIÓN}

El protagonismo judicial y la proliferación de medidas cautelares tiene directa relación con el lugar que ocupa el derecho en la vida social contemporánea. Comparado con épocas pretéritas, el derecho regula sectores de la vida que antes se encontraban regidos por la moral, por la religión o por normas consuetudinarias. Este proceso mediante el cual el derecho "conquista" nuevos territorios se conoce, en la moderna ciencia social, como "juridificación". Es un ejercicio de imaginación y percepción complicado descubrir en nuestra vida cotidiana ámbitos que no estén regulados normativamente: desde la vida familiar hasta la laboral, pasando por la educación y el deporte, todos ellos son terrenos profusamente reglamentados. La complejidad social obliga a regulaciones más específicas, la mayor parte de origen reglamentario, provocando una inflación normativa y la disminución paulatina del valor de la ley. Asimismo, se produce un cambio de orden cultural, creciendo la convicción de que ningún ámbito debe estar apartado de la juridicidad, lo cual explica la decadencia de teorías como la de las "cuestiones políticas no justiciables". Este crecimiento, tanto cualitativo como cuantitativo, lleva a una mayor litigiosidad social con el ejemplo paradigmático de los Estados Unidos, la "sociedad litigiosa" por excelencia. ${ }^{6}$ Si la juridificación se entiende en la relación del derecho con el resto de las normas sociales, la constitucionalización nos habla, en cambio, del peso relativo que la Constitución tiene en la conformación del orden jurídico, su creciente dominio del discurso jurídico.

\section{El juez, voz del derecho}

La juridificación, tal como se nos presenta hoy en día, sería una consecuencia inevitable del Estado de bienestar. El Estado asistencial, formulando o intentando dar aplicación a normas que buscan compensar un

6 Kagan, Robert, Adversarial Legalism. The American Way of Law, Boston, Harvard University Press, 2003. 
destino inmerecido o rectificando situaciones distributivas consideradas injustas, determina una expansión ilimitada de la producción normativa, cuyo resultado es una hiperreglamentación. A pesar del relativo consenso existente sobre los problemas derivados de la excesiva juridificación, una importante corriente de pensamiento la ve como una consecuencia de la implantación del Estado de derecho y, en tal sentido, como una derivación positiva del mismo. Lawrence Friedman, por ejemplo, la ve como un proceso por el que se expanden los derechos de justicia en la sociedad y no como una deficiencia estructural del Welfare State. Este autor parte de la premisa de que los cambios sociales llevan a cambios en la cultura legal, y eso es lo que a su vez produce cambios en el derecho. Para ejemplificar esta idea de las relaciones entre cambio social y cambio jurídico, Friedman plantea la cuestión en términos de oferta y demanda de servicios jurídicos. Si hay una gran producción de determinados bienes en nuestra sociedad - nos dice-, ello puede ser explicado de dos formas distintas. La primera es que el mercado ajusta la oferta y la demanda y, por lo tanto, la gran cantidad de bienes jurídicos existentes están ahí porque son necesarios para los ciudadanos. La segunda explicación sería que el mercado está distorsionado: algo en la estructura de la sociedad, o en las formas institucionales, hace que haya una superproducción de normas que no son necesarias. $^{7}$

El autor norteamericano se decanta por la primera explicación, y argumenta acerca de los cambios acaecidos en la cultura jurídica. La espiral de demandas y respuestas derivada de la temprana juridificación de diversas situaciones sociales ha acrecido la intervención normativa del Estado sobre esos ámbitos, y ello ha generado dos nuevos principios sociales:

...el primero es lo que podemos llamar una expectativa general de justicia; el segundo es una expectativa general de recompensa. El primero, brevemente, es la expectativa del ciudadano del trato justo, en todo lugar y en toda circunstancia. La justicia no es aquí una cuestión de procedimientos tribunalicios. La justicia es, o debería ser, alcanzable en todas las situaciones; en hospitales y prisiones, en escuelas, en el trabajo, en los edificios, en las calles, dentro de la familia. Es una penetrante expectativa de trato justo. Y es sustantiva tanto como procedimental. La segunda expectativa general está conectada de forma obvia con la primera. Es la expectativa general de que alguien pagará

7 Friedman, Lawrence M., Total fustice, Nueva York, Russell Sage Foundation, 1994, p. 15. 
por todas y cada una de las calamidades que le sucedan a una persona, suponiendo solamente que no ha sido falta de la persona o al menos sólo su falta. ${ }^{8}$

Esta expectativa general de justicia es un poderoso impulso de las medidas cautelares, en tanto instrumentos que tienden - de forma novedosa y temporalmente oportuna- a su satisfacción.

Si bien podría pensarse, de acuerdo con un esquema mecanicista, que el aumento de la juridificación por medio de la legislación debería significar un consecuente descenso de la actividad judicial, ello no es así. Y no lo es, porque por las mismas características que asume la legislación en la época actual, el papel del juez se ve sometido a una dinámica por la cual debe insertarse en el mecanismo de juridificación y cubrir las lagunas derivadas de las deficiencias estructurales de la labor legislativa, cuando las necesidades sociales de juridificación se hacen presentes. ${ }^{9}$ Del mismo modo,

...el aumento de las situaciones que la ley reconoce como jurídicamente relevantes se traduce en los hechos en un aumento de los casos en los que es necesaria la intervención del juez, precisamente a efectos de aplicar la nueva norma. La juridificación operada por medio de la legislación traslada al plano jurídico (o trae al interior del sistema jurídico) conflictos que antes solo existían en el plano de las relaciones sociales y económicas, y que, cuando se resolvían, lo eran según mecanismos y criterios extrajurídicos... En síntesis, por lo tanto, el incremento de la legislación no solo no reduce los conflictos, sino que multiplica las ocasiones en que estos deben ser resueltos por el juez. ${ }^{10}$

Los mecanismos de legitimación son, sin embargo, complejos. Recordemos que la ley, expresión de la voluntad general, y por consiguiente

$8 \quad$ Ibidem, p. 45.

9 En este sentido, en la literatura italiana se ha discutido mucho acerca de la figura de la "suplencia judicial", mediante la cual el juez, principalmente penal, asume la tutela directa de intereses ciudadanos ante la inactividad legislativa. Al respecto, ha expresado D. Pulitano: "La polaridad principal, que la llamada suplencia trae a colación, no es aquella entre justicia y administración, sino aquella entre formas legales y necesidades sociales de tutela de las que la magistratura se hace intérprete. La centralidad de la justicia penal es la consecuencia de una crisis de la legalidad, que está sobre todo en los hechos: en los abusos, en la inercia, en los delitos contra los que se debe reafirmar la potestad de la ley y en la mismas carencias y disfunciones del modelo legal de tutela" (Pulitano, Domenico, "Supplenza giudizaria e poteri dello Stato", Quaderni Costituzionali, año 3, núm. 1, 1983, p. 119).

10 Taruffo, Michele, "Note sui modi della giuridificazione", Politica del Diritto, año 18, núm. 4, 1987, p. 595. 
perteneciente al orden del poder, asume todavía un componente racional que la eleva por sobre el territorio de la nuda voluntad de un órgano de gobierno (el Parlamento) y de una clase social (la burguesía). ${ }^{11}$ De allí que la sujeción del juez a la ley no sea entendida desde la perspectiva de un sometimiento político, sino en tanto expresión de una adecuada delimitación de lo jurídico. La ley es, sobre todo, ordenación del marco de actuación de los individuos y perteneciente al derecho privado. El juez, ejecutor de este orden, "no puede aparecer, en consecuencia, como agente ejecutor de una política, sino como órgano enteramente ajeno a lo político. En la dualidad Estado-Derecho el juez se sitúa en este segundo y resulta en definitiva ajeno al Estado mismo, conceptualmente reducido al Monarca y a su aparato administrativo civil y militar". ${ }^{12}$ Esta postura explica, por lo tanto, que la independencia judicial haya sido concebida principalmente en referencia al Poder Ejecutivo y que sea recién en el momento en que se comienza a resquebrajar el esquema fundante de la voluntad parlamentaria como soberanía de la razón, cuando va a ser concebible un control de la actividad normativa.

El juez, como representante de la sociedad/derecho frente al Estado/ poder, es el núcleo central desde el cual se concibe esta consecución del Estado de derecho, y a esta visión obedecerá, por ejemplo, la conceptualización del derecho administrativo desde la perspectiva de su sometimiento a una jurisdicción independiente. En esta postura, derecho y juez son considerados sinónimos, con lo cual la concepción de la división de poderes se puede ver reducida a la independencia judicial, entendida ésta como un ámbito exclusivo donde se dice el derecho, pero que no se halla conectada directamente con los sistemas políticos. Contribuiría a ello, sobre todo en el ámbito europeo continental, la formación de una instancia de racionalización constitucional como una necesidad derivada de la propia fragmentación del sistema político subyacente y que se construye como una instancia independiente del proceso político. ${ }^{13} \mathrm{Al}$ conformarse

11 Expresiva de esta naturaleza bifronte de la legislación es la teoría de Guizot de la soberanía de la razón, mediante la cual fundamenta el sufragio censitario ( $c f r$. Chevallier, Jacques, "La dimensión symbolique du principe de légalité", Revue du Droit Public, núm. 6, 1990, p. 1651).

12 Otto, Ignacio de, Estudios sobre el Poder Fudicial, Madrid, Ministerio de Justicia, 1989, p. 176.

13 Porras Nadales, Antonio, Introducción a una teoría del Estado postsocial, Barcelona, PPU, 1988. 
la Constitución como una instancia racional, que no respondería directamente al proceso político - con lo cual no sufriría la deslegitimación instrumental de la legislación contemporánea-, sino que aparece como "orden de un contenido determinado, recto y, por ello, legítimo", ${ }^{14}$ el juez aparece como un intérprete superpuesto al juego de los poderes políticos. Esta característica de los órganos de control de constitucionalidad, que se deriva a los jueces inferiores a partir de la noción de vigencia efectiva de la Constitución en todos los casos jurisdiccionales, genera una separación del juez respecto del proceso político. Así, a través de una legitimación de orden jurídico, el Poder Judicial encuentra un campo de actuación diferenciado a partir del cual participa en los procesos de decisión pública. Ésta es la base de la intervención cautelar: un juez que pronuncia, con autoridad, una voz jurídica que interviene en un proceso de toma de decisiones eminentemente político.

\section{El juez y la articulación de la complejidad social}

La posición del juez en el sistema político se estructura en relación con la evolución que la producción legislativa ha sufrido desde los tiempos del régimen constitucional liberal. Por esta razón, para comprender adecuadamente la interrelación que se produce entre las funciones políticas y jurídicas del juez es necesario que retomemos las nociones que enunciamos respecto de la crisis de la ley como centro del circuito normativo. Al dejar la ley de lado su papel de referente racional mediante el cual se expresaba el derecho y asumir un papel instrumentalizador de los planes de transformación social de las mayorías en ejercicio del poder, comienza a ser necesaria una autoridad que equilibre los excesos a los que esa dinámica podía llevar. En otras palabras, mientras se confiaba en el Parlamento como expresión de la voluntad nacional, donde todas las posturas estaban representadas a través de la proporcionalidad de los sistemas electorales, no era de estricta necesidad contar con un poder externo que se contrapusiera a sus decisiones, porque la propia dinámica del juego de fuerzas parlamentarias tendería al contrapeso. ${ }^{15}$

\footnotetext{
14 Hesse, Konrad, Escritos de derecho constitucional, Madrid, Centro de Estudios Constitucionales, 1983, p. 15.

15 Confróntese esta idea con el análisis que hace Giovanni Sartori en Ingeniería constitucional comparada (México, Fondo de Cultura Económica, 1994).
} 
En la medida en que el mismo desarrollo del sistema político llevó a la necesidad de encontrar mecanismos que tendieran a esquemas mayoritarios con el fin de acrecentar la gobernabilidad, se pierde esa noción del Parlamento como lugar de consenso y de producción normativa racionalizada, y pasa a ser un sitio donde se genera un gobierno y una determinada dirección política comandada por la mayoría. Como dice M. Fioravanti:

...la misma evolución en sentido mayoritario conduce fatalmente a concebir el Parlamento-autor de la ley, no más como el lugar en el cual se recompone la identidad del pueblo soberano, como nuestros constituyentes pensaban, haciendo entre otras cosas derivar de tal convicción la necesidad del régimen proporcional, primera garantía de una legislación imparcial, sino más bien como el lugar en el cual se representa la existencia de una mayoría y una minoría, y en donde se persigue, con la ley, la realización del indirizzo político prevalente. ${ }^{16}$

La ley pierde así objetividad jurídica y también consenso social, ya que el propio mecanismo mayoritario supondrá la existencia de una alta proporción de ciudadanos que no encontrarán su opinión reflejada en la decisión parlamentaria.

Es a través de este proceso cuando comienza a resquebrajarse el legicentrismo decimonónico y empieza a hacerse patente la necesidad de una norma superior que condicione al Parlamento y una instancia que haga efectiva esa limitación. ${ }^{17}$ Coinciden así la instauración de los tribunales constitucionales y las teorías que le confieren fuerza normativa suprema a la Constitución, con la consiguiente ligazón entre una institución y la otra. Éste es el gran avance que se produce en el primer tercio de nuestro siglo,

16 Fioravanti, Maurizio, "Per un nuovo costituzionalismo", Democrazia e Diritto, núm. 1, 1997, pp. 267 y 268.

17 Señala Pedro de Vega que "el constitucionalismo decimonónico opera, una vez salvados los escollos iniciales, desde la creencia de que su construcción es tan perfecta que no necesita guardián de ningún tipo" (Vega García, Pedro de, "Jurisdicción constitucional y crisis de la Constitución", Revista de Estudios Políticos, núm. 7, 1997, p. 102). No es de extrañar, por lo tanto, que en la medida en que perdurara la vigencia de ese régimen no se haría efectiva la necesidad de establecer mecanismos externos de control. Será, por lo tanto, con los cambios sociales y políticos producidos a fines del siglo XIX cuando se romperá el equilibrio liberal y el sistema requerirá una revisión. En este sentido, se ha señalado la relación entre la inestabilidad política y el reforzamiento de los medios de control jurídico constitucional, hecho sobre el que ya había llamado la atención Carl Schmitt en su obra La defensa de la Constitución (Madrid, Tecnos, 1983). 
con su consolidación en la segunda posguerra: la ligazón entre Constitución y jurisdicción más allá de la mediación legislativa. Podemos afirmar con certeza que la fuerza normativa de la Constitución no fue formalmente discutida con anterioridad, sino que simplemente fue enmascarada por el papel mediador que asumió la Asamblea Legislativa. Y es al cortarse ese vínculo fundamental cuando el sistema se transforma en uno distinto, donde la ley ha perdido su lugar y se encuentra en la búsqueda de su inserción constitucional. En la tríada actual Constitución-leyes-Poder Judicial se encuentra la clave del circuito normativo.

Lógicamente, el papel del Poder Judicial ya no puede ser más el de un mero aplicador de la ley, porque en sus manos se encuentra la aplicación de la totalidad del sistema jurídico cuya cumbre es la norma constitucional. El juez - en especial el constitucional, pero no exclusivamente él- se ve obligado a ponderar entre la fuerza normativa de la Constitución y la mediación legislativa, y como resultado de esa ponderación asumirá - o no - un papel más activo en la resolución del caso. La aplicación directa de la norma suprema va a suponer así una morigeración de los efectos de la ley más allá de la efectiva declaración de inconstitucionalidad que en los sistemas de control concentrado se halla en manos del tribunal constitucional, a través de interpretaciones extensivas o restrictivas de las normas, sentencias aditivas, declaraciones de omisión legislativa y suplencia judicial. ${ }^{18} \mathrm{Al}$ mismo tiempo, la complejidad del sistema regulatorio legal le otorga, de forma indirecta, una gran discrecionalidad aplicativa que puede efectuar una interpretación de las normas que se adecúe a su visión de la Constitución sin necesidad de declarar o instar la declaración de inconstitucionalidad de las leyes en juego.

Ahora bien, la vigencia normativa de la Constitución se expresa sobre todo en el nuevo valor autónomo que adquieren los derechos individuales. Al separarse en su operatividad de la necesidad de ser consagrados por medio de la ley, van a ocupar un lugar en el ordenamiento que los hará inmediatamente efectivos y permitirá esgrimirlos frente a la estructura estatal. En este sentido, mientras la doctrina europea de los derechos públicos subjetivos hacía depender su existencia de la voluntad estatal y, por tanto, se reconducían a la expresión de la misma por los órganos correspondientes consagrando de ese modo la unidad del sistema jurídico y del

18 Rubio Llorente, Francisco, "La jurisdicción constitucional como forma de creación de derecho", Revista Española de Derecho Constitucional, núm. 22, 1988. 
Estado, la constitucionalización efectiva de los derechos individuales va a suponer una duplicación de las fuentes normativas y un conflicto potencial entre la actividad del Estado y los derechos de los ciudadanos. Este antagonismo, por principio, se hallaba negado en la construcción anterior por la mediación ejercida por el Legislativo, pero al aparecer la Constitución normativa como fuente de los derechos y emancipados éstos de las decisiones asamblearias, se hará necesaria una armonización entre las partes. Las medidas cautelares aparecen en este proceso como instrumentos al servicio de la protección de los derechos individuales, con fuerza suficiente para imponerse frente al proceso de toma de decisiones públicas.

Esta separación tajante entre ley y derechos obliga a un replanteo de las categorías jurídicas del constitucionalismo liberal, ${ }^{19}$ que debe hacerse desde el marco más amplio de las funciones que asumen las Constituciones en la época actual. En este sentido, a la tradicional función de garantía de los derechos y libertades que tenía la Constitución del Estado liberal de derecho, las normas fundamentales contemporáneas suman su condición de norma directiva fundamental, "que solidariamente compromete a todos en la obra dinámica de realización de los valores constitucionales". ${ }^{20}$ Mientras las primeras tenían como objetivo fundamental la limitación del poder, las actuales asumen una función integrativa de la sociedad a la que conforman, constituyendo y legitimando la autoridad política. ${ }^{21}$ Por esta razón, la Constitución no puede ser interpretada solamente desde una posición garantista de índole jurídica, porque perdería toda la riqueza de las nuevas formulaciones de principios y valores que señalan el camino del accionar del Estado y establecen sus deberes de actuación, condiciones que no quitan a su condición de norma jurídica el carácter político de las mismas.

He aquí una dialéctica de honda significación para nuestra reflexión sobre las medidas cautelares. En efecto, la importancia que éstas asumen obedece, en lo profundo, a que todo el ordenamiento comienza a ser interpretado exclusivamente como un sistema de garantías. En este caso, la Constitución queda limitada solamente al papel de norma jurídica y todos sus contenidos son juridizados a partir de las posiciones subjetivas

19 Ésta es la tarea que emprende Gustavo Zagrebelsky en su obra El derecho dúctil. Ley, derechos, justicia (2a. ed., Madrid, Trotta, 1997).

20 Fioravanti, Maurizio, op. cit., p. 128.

21 Preuss, Ulrich K., "The Conceptual Difficulties of Welfare Rights", en Sajo, A. (ed.), Western Rights? Post-Communist Application, Holanda, Kluwer Law International, 1996, pp. 176 y 177. 
reconocidas por su texto. Los derechos fundamentales son, de este modo, la clave única de interpretación del sistema, y su desarrollo, en conjunción con la fuerza normativa de la Constitución, hace que aquéllos imbuyan todo el sistema constitucional y que ello ahogue las restantes dimensiones constitucionales. De este modo, las normas de contenido objetivo son reinterpretadas en el sentido de constituir situaciones subjetivas de los ciudadanos, lo que "ha generado un proceso calificable de subjetivación del Derecho público, de suerte que hoy se considera que una norma reconoce un derecho subjetivo, siquiera de carácter reactivo, a poco que de la misma quepa inferir una protección de los intereses de los ciudadanos destinatarios". ${ }^{22}$ En la medida en que la subjetivización del derecho público contribuye a la creación de nuevos derechos en los ciudadanos y consiguientes obligaciones en cabeza del Estado, el juez tendrá una gran incidencia en la configuración del sistema político y en la determinación de las políticas públicas, ya que todas ellas serán analizables desde la perspectiva de las garantías. La distinción entre dirección política y límite jurídico queda difuminada, y la garantía dirige el proceso ahogando el margen de decisión discrecional y el ámbito reservado a la política.

\section{LA POSICIÓN DEL JUEZ}

En este contexto, la noción de "independencia judicial" es el último vestigio del "Antiguo Régimen" constitucional, un régimen en el que los jueces tenían un rol definido en el sistema a partir de la división tripartita de funciones alrededor de la ley (legislar, administrar, juzgar). Con la crisis de la ley, esa división es puesta en duda, y los jueces comienzan a tener una relevancia en el esquema de gobierno, que torna irónica la frase montesquiana de ser "la boca que pronuncia las palabras de la ley". ${ }^{23}$ Tal como venimos describiendo, la dimensión cuantitativa de su intervención ha crecido exponencialmente, así como lo ha hecho la naturaleza misma de su función. Hoy en día, los jueces actúan con una mirada más prospectiva que retrospectiva, ya que los efectos de sus sentencias se expanden más allá de las partes del proceso y asumen funciones que exceden largamente las conectadas

22 Parejo Alfonso, Luciano, Crisis y renovación en el derecho público, Madrid, Centro de Estudios Constitucionales, 1991, p. 70.

23 Montesquieu, Barón de, op. cit., p. 112. 
tradicionalmente con lo jurisdiccional. ${ }^{24}$ En concreto, el juez comienza a tener un involucramiento mayor en el proceso de discusión y armado de las políticas públicas y, en el marco de una sociedad mediática, su accionar adquiere una visibilidad pública hasta hace poco desconocida. Su poder se adecua a esta nueva dinámica, y ello genera la aparición de nuevas dimensiones de actuación. Parafraseando a los autores de El Federalista, el Poder Judicial no tiene ni la bolsa ni la espada, ${ }^{25}$ pero sí tiene la palabra, palabra que dice el derecho (iurisdictio), y que conforma la vida social. A través de ella, los jueces construyen legitimidad para sí y establecen criterios para los otros poderes. Esta legitimidad —o "capital social" - va a ser el recurso del cual se van a valer los jueces para intervenir en la realidad sociopolítica, terreno antes reservado a los funcionarios electivos. Pero, por otro lado, va a ser la mayor conexión con la sociedad la que le va a "imponer", en algún sentido, su actuación cautelar. El juez, así, ya no puede permanecer indiferente al devenir de la sociedad a la que pertenece. Debe, en virtud de estos imperativos, contribuir a la realización de los derechos constitucionales.

Si hay algo que caracteriza a nuestra era es el cambio a una velocidad vertiginosa. ${ }^{26}$ Circunscribámonos al último medio siglo. Las sociedades desarrolladas han pasado, en expresión de Inglehart, ${ }^{27}$ de tener valores "materialistas" (o de "supervivencia": bienestar económico, seguridad militar, orden interno) a valores "postmaterialistas" (o de "autoexpresión": medio ambiente, calidad de vida, derecho a la definición de la propia personalidad, desarme). Ese cambio cultural se ha reflejado en la erosión de las identidades fijas, el corrimiento de las posturas ideológicas, el descrédito de las instituciones públicas y la creciente importancia de las emociones en la vida pública y privada. Concomitantemente, en el plano político, se han producido profundas transformaciones en las relaciones de representación

24 Desarrollamos estas ideas en Thury Cornejo, Valentín, Juez y división de poderes hoy, Buenos Aires, 2002. En el mismo sentido, cfr. Guarneri, Carlo y Pederzoli, Patrizia, Los jueces y la política. Poder Fudicial y democracia, Madrid, Taurus, 1999.

25 Hamilton, Alexander et al., El Federalista, México, Fondo de Cultura Económica, 1994, núm. 78.

26 Friedman, Lawrence M., Ahora elijo yo. La república de las opciones infinitas, Buenos Aires, Grupo Editor Latinoamericano, 1992; Koselleck, Reinhart, “¿Existe una aceleración de la historia?", en Beriain, Josetxo y Aguiluz, Maya (eds.), Las contradicciones culturales de la modernidad, Barcelona, Anthropos, 2007.

27 Inglehart, Ronald, Modernización y posmodernización. El cambio cultural, económico y politico en 43 sociedades, Madrid, CIS, 1998. 
política a raíz del declive de los partidos políticos, de la mediatización de la esfera pública y de la fragmentación de lo público en una multiplicidad de intereses dispersos. ${ }^{28}$ Para hacer más complejo el panorama, habría que sumar al mosaico la creciente conciencia de la complejidad de los asuntos públicos debida a la interrelación de una multiplicidad de esferas de acción, que para su solución requieren articulación al mismo tiempo que especialización funcional. En este contexto, la capacidad de hacer elecciones prospectivas se reduce, y el Estado deja de lado su intento de formular un modelo general y estable de racionalidad vertical, y la sociedad adopta una organización fragmentaria donde los diferentes reclamos de participación son articulados.

El juez, justamente, aparece como una figura que puede realizar, en los casos concretos, esa articulación - que se da en el marco de una temporalidad teñida por la urgencia que justifica la intervención cautelar-. Urgencia y complejidad social producen así la aparición de nuevos actores sociales y nuevos modos de intervención, que tratan de lidiar con esas demandas que el sistema le realiza a los jueces. ${ }^{29} \mathrm{Su}$ papel cambia porque también lo hace la función del derecho que él está llamado a aplicar. Lejos del modelo abstencionista decimonónico, el derecho se transforma en un instrumento de dirección social. Aquí, la conceptualización de los tres tipos de derecho - represivo, autónomo y receptivo - que realizan Nonet y Selznick puede sernos de ayuda. ${ }^{30}$ Cada uno de los tres se distingue del otro por el propósito, el método y la fuente de legitimidad. El objetivo del primero es el orden y, en él, el derecho se halla directamente subordinado a la política; es un instrumento para la construcción de poder político. Como tal, es sumamente discrecional, tiene poca previsibilidad y múltiples excepciones, y sus normas son dictadas con poca participación

28 Thury Cornejo, Valentín, "La legitimidad de los tribunales supremos y sus estrategias comunicativas. El caso de de la Corte Suprema de EE.UU.”, Estudios Constitucionales, año 7, núm. 2, 2009.

29 Un ejemplo de esta dinámica es la aparición del litigio de interés público en el ámbito estadounidense (Sabel, Charles F. y Simon, William H., "Destabilization Rights: How Public Law Litigation Succeeds", Harvard Law Review, vol. 117, 2004), y su posterior implementación en otras latitudes; por ejemplo, en Argentina ( $f f r$. Centro de Estudios Legales y Sociales, La lucha por el derecho. Litigio estratégico y derechos humanos, Buenos Aires, Siglo XXI Editores, 2008).

30 Nonet, Philippe y Selznick, Philip, Law E Society in Transition: Toward Responsive Law, 2a. ed., Nueva York, Octagon Books, 2001. 
ciudadana. El derecho autónomo intenta remediar estos defectos, limitando el poder represivo del Estado. Ante las demandas públicas de una mayor legitimidad, establece un sistema uniforme de aplicación de reglas con una cierta independencia del sistema político y pone el énfasis en la regularidad procedimental de formación y aplicación del derecho. Esta tipología es la que se encuentra descrita en la caracterización que Max Weber hace de la dominación legal-racional, como característica de la modernidad ${ }^{31}$ o describimos, más comúnmente, con la frase "gobierno de las leyes, no de los hombres".

El derecho receptivo, por su parte, expresa una fase evolutiva posterior, que retorna a los fines sustanciales de la sociedad frente a la tendencia del derecho autónomo a considerar los objetivos de éste como fines en sí mismos. Así, el derecho receptivo trata de dar cuenta de las tensiones entre la búsqueda de la justicia y las limitantes formales que se derivan del derecho autónomo. Este último, con su relativo aislamiento de las dinámicas sociales que se expresan en el sistema político, tiende a anquilosarse. Su estabilidad, de este modo, es, por un lado, un factor de orden del sistema, pero tiende a deslegitimarse ante la irrupción de cambios sociales, económicos y culturales, que requieren una adaptación sustancial del derecho aplicado. ${ }^{32}$

31 Weber, Max, Economía y sociedad. Esbozo de sociología comprensiva, México, Fondo de Cultura Económica, 1979, pp. 170 y ss.

32 En palabras de Nonet y Selznick (ibidem, p. 14), el derecho responsivo se presenta como "un facilitador de respuestas para las necesidades y aspiraciones sociales". Si bien los tres tipos de derecho suelen convivir en un sistema jurídico concreto, existe una lógica evolutiva por medio de la cual un determinado esquema va generando incentivos para que se desarrolle una etapa que brinde soluciones a los problemas por ellos planteados. Así, la crítica al derecho represivo y la necesidad de brindar estabilidad al sistema para lograr, por ejemplo, un mayor desarrollo económico, sienta las bases para la autonomización del derecho. Una vez lograda y consolidada esta etapa, nuevos desafíos se van formando en distintas partes del sistema, que tienden a reordenar las relaciones estabilizadas por el derecho autónomo. Desde este punto de vista, esta evolución del derecho se traduce en la omnipresente discusión "activismo vs. autorrestricción" judicial, que no hace más que expresar, bajo la forma de ideologías judiciales contrapuestas, tensiones estructurales del derecho contemporáneo. A lo largo de este trabajo, intentaremos abstraernos de esa discusión normativa - ¿deben los jueces ser más activos o autorrestringirse? - para concentrarnos en los cambios que explican los cambios en la función judicial, o sea, por qué los jueces hoy tienden a ser más activos que hace unas décadas. Nuestra postura no elimina la discusión antes mencionada, pero permite contextualizarla en un marco que explica la tendencia hacia el activismo judicial y así, en cierto modo, relativizarla. Esto es así, porque la decisión sobre ser activo o autorrestringirse no depende enteramente de la voluntad del magistrado, sino 
El derecho receptivo brinda los canales a través de los cuales estos cambios pueden ser incorporados, mayormente a través del poder decisorio de los jueces. De este modo, el derecho receptivo borra las claras líneas demarcatorias que el derecho autónomo fijaba entre lo jurídico y lo político, ya que para realizar la función de articulador entre el derecho y las necesidades sociales, el juez deberá transgredir los restringidos límites de un derecho cerrado en sí mismo e incursionar en formas activas de decisión. Para ello, debe redefinir sus funciones. ${ }^{33}$ En efecto, las normas constitucionales, diseñadas para un entorno de mayor unidad y simplicidad social, garantizan - en mayor o menor medida - ciertas prerrogativas que separaban al juez de las ramas políticas. En ese contexto, la ecuación entre derecho y sociedad era un dato de la realidad, y el juez sólo debía, de modo más o menos complejo, aplicarla.

Hoy, en cambio, la sociedad se hace múltiple, las fuerzas se dispersan, los mecanismos de control se multiplican, el Estado se hace poroso a la intervención social, y esa ecuación se rompe. ${ }^{34}$ Por consiguiente, la relación entre derecho y sociedad necesita ser construida, y junto con ella va a tener que redefinirse el papel del juez, que va a ser justamente el que realice esa articulación. Y lo hará por medio de su modo natural de acción; ello es, a través de sus decisiones concretas al resolver casos van a tratar de ir armonizando las necesidades de estabilidad del sistema y las de cambio social. O, en el lenguaje de Nonet y Selznick, que venimos siguiendo, van a ir mediando entre un derecho autónomo y un derecho responsivo, y lo va a hacer a través de aproximaciones sucesivas, de carácter experimental y participativo. En efecto, las medidas cautelares se configuran como instrumentos de intervención judicial no definitivo, acordes con el nuevo rol que los magistrados desempeñan. En el marco de un sistema democrático, las nuevas funciones judiciales no pueden ser realizadas del mismo modo que en un contexto de derecho autónomo. En éste, el juez se refugiaba en el papel sacerdotal que cumplía, como intérprete del texto "sagrado" de

que es una decisión condicionada por los cambios estructurales producidos en la configuración del derecho y del entramado institucional.

33 Barak, Aharon, "A Judge on Judging: The Role of a Supreme Court in a Democracy", Harvard Law Review, vol. 116, 2002.

34 El pluralismo social requiere mayores dosis de integración, las cuales deberían ser provistas por la Constitución y por los jueces que la interpretan (Grimm, Dieter, "Integration by Constitution", I-CON International fournal of Constitutional Law, vol. 3, núms. 2 y 3, 2005). 
la Constitución y aplicaba las normas y rituales de su profesión de forma distante y severa. Su público estaba configurado, esencialmente, por la comunidad jurídica y por los actores políticos implicados en sus decisiones. La fortaleza del discurso autónomo era tal que las modulaciones propias de la actividad judicial podían ser manejadas a través de la retórica con que eran expresadas. ${ }^{35}$ En la medida en que los procesos de transformación avanzan, los jueces no pueden refugiarse más en una fuente de autoridad autónoma y mítica, y deben abrirse, en mayor o menor medida, a la sociedad con la que deben interactuar.

En este sentido, Aharon Barak, presidente de la Corte Suprema israelí, sostiene que una de las condiciones esenciales del ejercicio de la judicatura es la confianza pública en el juez, "confianza en su independencia, justicia e imparcialidad" porque al no tener recursos materiales para distribuir, ese es su único capital. ${ }^{36}$ Ello es, una confianza que denota mayor conexión con el público, pero, al mismo tiempo, responde a las características esenciales de su función y le permite articular nuevos mecanismos de diálogo social. ${ }^{37}$ Las intervenciones inmediatas en la realidad pública, en tiempo presente - frente al carácter ex post tradicional-, sugieren una apertura del proceso hacia la complejidad de la realidad social, haciendo de las medidas cautelares un instrumento de interacción de saberes y actores, según veremos seguidamente al hablar del litigio estratégico. La trascendencia de sus decisiones "arroja" a los jueces a la esfera pública mediatizada, que no es más “...solamente un vehículo a través del cual aspectos de la vida política y social son traídos a la atención de los otros, sino que se ha transformado en el medio principal en que las luchas políticas y sociales son articuladas y llevadas a cabo". ${ }^{38}$ Los jueces necesitan de la conexión con la sociedad para lograr apoyo a sus decisiones de cambio social, al mismo tiempo que es en ese terreno donde el resto de los poderes políticos van a discutir sus decisiones. Es allí donde van a tener que obtener la legitimidad social que avale sus decisiones, así como previamente la obtenían de la "cientificidad" del derecho que aplicaban.

35 Thury Cornejo, "La legitimidad de los tribunales supremos...", op. cit.

36 Barak, Aharon, op. cit., p. 59.

37 Eskridge, William N. y Ferejohn, John, "Constitutional Horticulture: DeliberationRespecting Judicial Review”, Texas Law Review, vol. 87, 2009.

38 Thompson, John B., "The New Visibility", Theory, Culture Ë Society, vol. 22, núm. 6, p. 49. 


\section{MODOS DE INTERVENCIÓN JUDICIAL}

No cabe duda que este nuevo contexto es producto de que el sistema de gobierno democrático ha sufrido numerosas transformaciones. Por mencionar solamente tres de gran relevancia para nuestro objeto de estudio: a) una gran crisis de legitimidad de las instituciones representativas, que pone muchas veces en jaque el andamiaje organizativo sobre el que se basan nuestras democracias; b) un profundo proceso de transformación del Estado, de sus funciones y de sus modos de intervenir sobre la realidad que aún no encuentra un estadio de forma definitivo: del Estado de bienestar al Estado mínimo, y, ahora, el círculo parece volver a empezar, pero se entrecruza con otros procesos que llevan del Estado central a la descentralización y a la globalización concomitantes, y c) un creciente reconocimiento normativo de los derechos humanos, que penetran los ordenamientos jurídicos nacionales y los vinculan, a través de los tratados, a los órganos de interpretación internacionales. No es nuestro objetivo aquí analizar estos procesos, sobre los que tanto y muy bueno se ha escrito. Simplemente, entendemos que es necesario tomar conciencia de este movimiento de capas tectónicas para adecuar los esquemas y expectativas constitucionales a los que atamos la actuación de los poderes del Estado. Entre ello, y en lo que aquí compete, a los jueces. Por este motivo, hablar de los derechos constitucionales supone necesariamente plantear cuál es la función de los jueces a su respecto, en el entendimiento de que dicha función no puede ser más - exclusivamentela de aplicar una norma prefijada y cierta como la que proveían los códigos decimonónicos. Caer en ello supondría una visión simplista y esquemática de un modelo que no refleja adecuadamente el modo en que las políticas públicas se configuran en la actualidad.

En este sentido, varios son los modelos que se han intentado para dar cuenta de estos procesos. Nos ocuparemos seguidamente de dos de ellos: el del litigio estratégico y el de la nueva gobernanza. Si bien tienen varios puntos en común, sobre todo en lo que hace al intento de conceptualizar de un modo nuevo las funciones judiciales, los trataremos por separado porque hacen referencia a dos fenómenos parcialmente diversos. El litigio estructural se relaciona más directamente con la efectiva vigencia de los derechos constitucionales, siendo justamente ese litigio el modo en que se trata de modificar una realidad no acorde con esos parámetros. El caso típico, citado por toda la literatura, es Brown vs. Board of Education, mediante el cual se puso en jaque el sistema de desagregación de las personas de 
raza negra en las escuelas públicas de Estados Unidos. Los fenómenos de la nueva gobernanza se ocupan, más directamente, de las nuevas formas en las que el Estado interviene en la realidad, trascendiendo las categorías clásicas de atribución de funciones de gobierno. En la actualidad, el circuito de decisiones públicas deja ser entendido como un mecanismo lineal y pasa a ser conceptualizado como una forma de nuevo experimentalismo social, como modos de ir aproximándose deliberativamente a la solución de problemas complejos. ${ }^{39}$ Los estudios más clásicos en este terreno son los relacionados con esquemas de gobierno organizativamente complejos, como la Unión Europea. ${ }^{40}$

\section{El litigio estratégico}

Según Basch, "el objeto distintivo del litigio de reforma estructural es la eliminación o modificación de condiciones estructurales que dan lugar a una determinada situación de hecho - compleja, producto de distintas decisiones de múltiples agencias - que resulta violatoria de derechos". ${ }^{41}$ A estos derechos, Sabel y Simon, en el ámbito anglosajón, los han teorizado a partir de una definición de Roberto Mangabeira Unger como "derechos desestabilizadores". Así, los mismos son vistos como "demandas para perturbar y abrir instituciones públicas que de forma crónica han incumplido con sus obligaciones y que están sustancialmente aisladas de los procesos normales de responsabilidad (accountability) política". ${ }^{42}$ Formalmente, va a ser el objeto mismo del proceso el que va a modificar su estructura: ya no estamos propiamente ante dos partes, actora y demandada, ante las

39 La obra de Charles Sabel es una referencia ineludible de esta línea de pensamiento. Cfr. Dorf, Michael C. y Sabel, Charles F., "A Constitution of Democratic Experimentalism”, Columbia Law Review, vol. 98, núm. 2, 1998, y Liebman, James S. y Sabel, Charles F., "A Public Laboratory Dewey Barely Imagined: The Emerging Model of School Governance and Legal Reform", New York University Review of Law \& Social Change, vol. 28, 2003.

40 Sabel, Charles F. y Zeitlin, Jonathan, Experimentalist Governance in the European Union. Towards a New Architecture, Oxford, UK, Oxford University Press, 2010.

41 Basch, Fernando, "Breve introducción al litigio de reforma estructural", documento base para el seminario Remedios fudiciales y Monitoreo de Ejecución de Sentencias en el Litigio de Reforma Estructural, Facultad de Derecho de la Universidad de Buenos Aires, 4 y 5 de noviembre de 2010.

42 Sabel, Charles F. y Simon, William H., "Destabilization Rights...”, op. cit., p. 1020. 
cuales el juez debe definir la prestación discutida, sino que nos hallamos ante un grupo de actores afectados por una situación estructural compleja. En la República Argentina, el caso Mendoza, sobre la contaminación del Riachuelo, puede ilustrarnos sobre estas características. Multiplicidad de demandados (Estado Nacional, Giudad de Buenos Aires, Provincia de Buenos Aires, municipios, empresas radicadas en la zona, etcétera) y un objeto procesal que requiere para su solución - terminar con la contaminación ambiental- de una política pública articulada entre esos diversos actores y a ser efectivizada en el mediano-largo plazo.

Los casos de litigio estratégico se presentan como "litigios policéntricos", al decir de Fuller, ${ }^{43}$ en los que participan organizaciones de la sociedad civil y actores institucionales de nuevo cuño constitucional (por ejemplo, Defensor del Pueblo, Ministerio Público, ONGs, etcétera). Esta ampliación de la participación y el objeto procesal complejo generan la necesidad de nuevas formas procesales que permitan manejarla, quedando muchas veces ellas en manos de los mismos jueces como un derivado de su capacidad/obligación de dirigir el proceso. A ello debe sumarse la duración del proceso, debido a que las transformaciones estructurales perseguidas en este tipo de juicio requieren a veces varios lustros de implementación y trabajo judicial. Volviendo a la actuación de la actual Corte Suprema argentina, vemos cómo nuevas formas procesales (audiencias públicas, normas abreviadas para la contestación de demanda, amicus curiae, etcétera) se entrelazan con la participación de organizaciones sociales que aportan visibilidad y conocimiento técnico a la tarea del tribunal. El juez pasa a asumir así un rol de articulador de una política pública que generarán los poderes públicos responsables, en vez de presentarse como el órgano aplicador de una solución jurídica definitiva. Su función varía como lo hace la funcionalidad institucional de los litigios estructurales. Al decir de Rodríguez Garavito, estos procesos pueden satisfacer varios fines - alternativa o conjuntamente- , sea de forma directa o indirecta, o en la esfera material o simbólica: ${ }^{44}$

43 Fuller, Lon, "The Forms and Limits of Adjudication", Harvard Law Review, vol. 94, 1978, p. 368.

44 Rodríguez Garavito, César, "Beyond the Courtroom: The Impact of Judicial Activism on Socioeconomic Rights in Latin America", Texas Law Review, vol. 89, 201 1, p. 1679 . 
Esta revista forma parte del acervo de la Biblioteca Jurídica Virtual del Instituto de Investigaciones Jurídicas de la UNAM

\begin{tabular}{|c|l|l|}
\hline & \multicolumn{1}{|c|}{ Directa } & \multicolumn{1}{c|}{ Indirecta } \\
\hline Material & Diseño de política pública & Formación de coaliciones \\
\hline Simbólica & $\begin{array}{l}\text { Definición de problema co- } \\
\text { mo violación de derecho. }\end{array}$ & $\begin{array}{l}\text { Transformaciones en la esfera } \\
\text { pública sobre la gravedad del } \\
\text { problema. }\end{array}$ \\
\hline
\end{tabular}

\section{La "nueva gobernanza"}

Esta variedad de posibles efectos del litigio estratégico, que se apartan de la tradicional sentencia atributiva de sanciones o responsabilidades jurídicas, se emparenta con lo que muchos autores han calificado como "experimentalismo democrático". Bajo este mote, autores como Charles Sabel hacen referencia al cambio del paradigma de regulación basada en el binomio "orden y control", a uno donde las reglas son más flexibles y provisionales, con mayor participación de los involucrados en el proceso y la posibilidad de una responsabilidad calculable. Para Sabel y Simon, este cambio es una forma de lidiar con la falta de certeza sobre las soluciones a los problemas públicos y, aún más, a su misma definición, ya que el proceso no es visto como una determinación del conocimiento o de la solución correcta, sino como un proceso de aprendizaje que se va a acercando a esas definiciones a través del monitoreo constante y el mejoramiento consiguiente, tal como ha expresado en el campo de la organización económica el modelo de producción Toyota. ${ }^{45}$ La provisionalidad y revisabilidad de las políticas es una de las características principales de lo que la literatura conceptualiza como "nueva gobernanza", ${ }^{46}$ concepto que, en toda su vaguedad, busca dar cuenta de las nuevas formas de regulación de los asuntos públicos, en un contexto crecientemente descentralizado y, al mismo tiempo, globalizado, con actores poderosos, que condicionan la acción de un Estado sin los recursos económicos y/o de monopolio de la fuerza que le permitan actuar por sí mismo. Ello genera nuevas formas de regulación, donde la colaboración y la fijación de incentivos para actuar en un sentido determinado cobran relevancia frente a lo que antes eran directivas basadas en el puro imperio estatal.

45 Sabel, Charles F. y Simon, William H., "Destabilization Rights...", op. cit.

46 De Búrca, Gráinne y Scott, Joanne, "New Governance, Law and Constitutionalism", en De Búrca, Gráinne y Scott, Joanne (eds.), Law and New Governance in the EU And The US, Oxford-Portland, Hart Publishing, 2006. 
Este nuevo escenario, que convive con las formas anteriores, está en pleno desarrollo, y marca la necesidad de adecuar la actuación de las instituciones a estas nuevas modalidades. Scott y Sturm, por ejemplo, han visto la función de los jueces en estos procesos como catalizadores de la toma de decisión pública, a través de tres actuaciones concretas: a) el control y puesta en ejercicio de la participación de todos los posibles afectados y/o involucrados en el proceso de toma de decisión; b) el monitoreo de la adecuación de la base informativa para la toma de decisión, a través del control de legalidad de determinadas medidas, y c) el control de la transparencia y los mecanismos de responsabilidad en la implementación de las políticas públicas. ${ }^{47}$ Este intento de sistematización, a partir de la experiencia europea, tiene el valor de utilizar las categorías e instrumentos disponibles para dar cuenta de los procesos que se dan en la realidad de gobierno. De otro modo, la complejidad de los problemas que deben solucionar y de las nuevas modalidades de acción pública termina por vaciar de contenido a esa acción, ya que los jueces acaban por carecer de mecanismos efectivos para controlarlos. Estos nuevos modos de pensar el esquema son intentos de salir del dilema de la judicialización o del activismo judicial como una expropiación por parte de los magistrados de facultades de la administración o del Legislativo. Eso existe y, probablemente, lo seguirá haciendo, pero no debe ocultar los desafíos estructurales a los cuales la complejidad del gobierno actual hace que los jueces se enfrenten.

La teorización acerca del litigio estratégico o de la nueva gobernanza ayudan a conceptualizar direcciones en las que el funcionamiento del sistema jurídico se está moviendo. Ello no significa una valoración positiva o un abrazar estas instituciones como un norte hacia el que debemos dirigirnos. Antes bien, lo que intentamos hacer es ayudarnos de estos modelos para incentivar nuestra capacidad de pensar el rol de los jueces y de los instrumentos que utilizan en un entorno en el que el contexto de su función ha variado enormemente. Porque en el fondo lo que estamos discutiendo aquí son los viejos temas del derecho constitucional: ¿qué es lo que dice la Constitución?, y ¿quién es la voz autorizada para fijar ese significado? Una visión un tanto esquemática nos diría, como ya adelantamos, que ese significado se encuentra inscrito en el texto, y que es el juez quien debe de-

47 Scott, Joanne y Sturm, Susan, "Courts as Catalysts: Re-Thinking the Judicial Role in New Governance", Columbia fournal of European Law, vol. 13, 2006. 
terminarlo, y así controlar la constitucionalidad de las normas y actos del poder administrador. Una versión más matizada, en cambio, reconocería que ese significado no se encuentra concretado totalmente en la norma, y que, por lo tanto, debe ser concretado en un proceso posterior. En el medida en que ese proceso engloba actividades del resto de los poderes e involucra el diseño e implementación de políticas públicas, la participación de los jueces será necesaria, pero no excluyente. Así, por ejemplo, determinar el contenido concreto del derecho a la salud o a la educación frente a una política pública que determina prestaciones médicas obligatorias o acceso a las escuelas públicas es un proceso de diálogo constitucional de estructura compleja, que obliga a repensar los esquemas tradicionales acción administrativa-control judicial.

\section{LEGITIMIDAD SOCIAL DEL JUEZ}

La realidad nos muestra la aparición de procesos y nuevas funciones que distan de la interpretación tradicional de la estructura institucional. Ante esto cabe preguntarse si ellas han perdido vigencia o simplemente han cambiado su relación con el contexto. Nuestra hipótesis es que la mediatización de la vida democrática y la inserción del juez en el centro de esa vida provocan una transformación de la función de las normas institucionales. La dinámica comunicativa y la institucional se solapan y adoptan formas de interacción complejas que tornan necesario incorporar nuevos elementos que expliquen la construcción del rol judicial y, consiguientemente, de la acción administrativa. Las normas ya no bastan. En el esquema tradicional existe una simetría entre forma - procedimiento constitucional- y contenido - proceso político-, donde el primero resulta el marco adecuado para que el segundo se desenvuelva. Hoy en día, en el marco de una sociedad mediatizada, ${ }^{48}$ el sistema institucional formal no monopoliza el devenir de esos procesos políticos, y la simetría se resquebraja. La realidad política se desenvuelve en gran parte fuera de los cauces institucionales. El rol del proceso formal pasa a ser una validación de lo sucedido en esta esfera mediática, que a veces se da, de forma compleja, con carácter simultáneo y,

48 Couldry, Nick, "Mediatization or mediation? Alternative understandings of the emergent space of digital storytelling", New Media \& Society, núm. 10, 2008, y Strömback, Jesper, "Four Phases of Mediatization: An Analysis of the Mediatization of Politics", The International Fournal of Press/Politics, núm. 13, 2008. 
otras veces, se produce con carácter sucesivo. ${ }^{49}$ En uno y otro caso, el resultado de la discusión pública pasa a ser un insumo ineludible del proceso deliberativo institucional.

Esta circunstancia pone de relieve que el análisis de organización institucional debe necesariamente cruzarse con lo que sucede en esa esfera pública, con los procesos que allí se desarrollan y con los recursos con los que cuentan sus actores. En ese campo es donde los jueces construyen su legitimidad (otro nombre con el que podemos denominar la confianza a la que hacía referencia Barak). Es esa legitimidad la que, eventualmente, va a ser evaluada por el sistema institucional, y admitirá la intervención judicial en los procesos de toma de decisiones públicas. Ahora bien, ¿cómo se construye esa legitimidad? Si tomamos la definición de Suchman - "percepción o suposición generalizada de que las acciones de una entidad son deseables, correctas o apropiadas dentro de un sistema socialmente construido de normas, creencias y definiciones" — ${ }^{50}$ nos encontramos con dos términos - acciones y sistema normativo/cultural-y una relación de adaptación entre ambos. Pues bien, en el pasado, ese sistema normativo venía prefigurado por las normas formales que definían el rol que los jueces debían tener, a partir de un esquema en el que ellos - en un sistema de control difuso - "interpretaban y aplicaban" las normas constitucionales. Si bien tradicionalmente el margen de acción del intérprete fue mayor en el derecho constitucional que en otras ramas, esa discrecionalidad se ha acrecentado contemporáneamente justamente por el proceso de constitucionalización del derecho. ${ }^{51}$ Ergo, hoy más que nunca, el juez goza de amplios poderes de autodefinición, al menos desde el punto de vista de los instrumentos jurídicos que utiliza, cuestión que repercute directamente en la expansión del uso de las medidas cautelares.

El juez, entonces, se autodefine y lo hace en una doble dimensión: jurídico-institucional y simbólica, facetas que expresan su carta de ciudadanía en la esfera pública y en la institucional. Pero los jueces no construyen su imagen simbólica desde la absoluta creatividad, sino que a través de

49 Véase una aplicación de esta dinámica para la actividad parlamentaria en García Morillo, Joaquín, "El parlamento en la era global”, Cuadernos de Derecho Público, Madrid, núm. 1, 1997.

50 Suchman, Mark, "Managing Legitimacy: Strategic and Institutional Approaches", The Academy of Management Review, vol. 20, núm. 3, 1995, p. 574.

51 Favoreu, Louis, "La constitucionalización del derecho", Revista de Derecho, vol. XII, 2001. 
ella procesan y moldean el significado que se les atribuye a sus decisiones materiales. Estas últimas suelen reconocer las limitaciones fácticas derivadas de su poder real para imponer su voluntad en un momento determinado. Los jueces no actúan en el vacío, sino que lo hacen en el marco del resto de poderes democráticos, a los cuales limitan y por los cuales se ven limitados. Desarrollar la identidad del tribunal, ello es, construir las normas y creencias que definan su función y a partir de las cuales se medirán sus acciones, es una tarea que se hace de cara al resto de los poderes actuantes. Las normas determinan su lugar en el esquema de poderes, las garantías para su funcionamiento y los instrumentos de poder efectivo de que dispone, y es a partir de ellos como el Tribunal se autoconstruye. ¿Cuál es entonces su nota característica frente a los poderes políticos? Hace un tiempo, podríamos haber dicho que el Poder Judicial era un órgano jurídico y que se diferenciaba por esta nota de las ramas de gobierno. Hoy, como hemos visto, esta línea divisoria se ha hecho más tenue, y si bien no ha perdido sentido orientador, dificulta la creación de una identidad que se base en las funciones que los tribunales efectivamente hacen en la práctica. Por otra parte, sabemos bien que los restantes órganos de gobierno también crean y aplican el derecho. Entonces, podríamos afirmar que su nota diferencial está en la falta de medios de fuerza para imponer sus decisiones, característica negativa inversamente proporcional al poder simbólico de su tarea central.

Si miramos a los jueces desde esta perspectiva, encontramos que muchas de sus notas constitutivas se pueden condensar en su lógica más primaria: la de una institución que "dice" no que "hace", a diferencia de los poderes políticos (Ejecutivo y Legislativo), que son los que "hacen" cosas y, así, gobiernan. Probablemente carente de recursos materiales (presupuesto, fuerza ejecutoria, sanción normativa de carácter general) por su falta de legitimación democrática directa a través de elecciones, adquiere una estabilidad y garantías de funcionamiento de la que no disponen el resto de los poderes. Existe así una relación de adecuación lógica entre sus recursos y sus garantías, que la circunscriben a una tarea discursiva de largo plazo, propia, por otra parte, de la vigencia del bien - ordenamiento legal y Constitución - que está destinada a proteger. En cuanto a su posicionamiento relativo, entonces, los jueces no están inermes: al hablar se construyen a sí mismos y construyen al resto de los poderes. Podríamos decir, en este sentido, que su necesidad de autodefinición tiene un sesgo 
recursivo: el juez se define para definir. A través de su discurso, el tribunal fija los límites de legitimidad de los otros poderes. Interpreta el derecho y la Constitución, y así administra, simbólicamente, uno de los bienes más preciados del sistema político: la determinación de las normas de conducta a la que los otros actores deben adecuarse para reputarse legítimos. En este sentido, al menos, nominar es dominar, ${ }^{52}$ y es lógico que la actuación de los jueces esté muchas veces en el centro de relevantes batallas políticas. Para sostenerse, deben construir su propia legitimidad. Y ésta deberá ser consistente con su autodefinición, ya que será a ésta - o como ella es percibida por el público - a la que deberá responder en su actuación.

Esa construcción identitaria, según ya vimos, debe ser coherente con las normas constitucionales y con el sistema que ellas instauran. Pero eso no alcanza, si el rol que de allí se desprende no responde a las concepciones sociales respecto de sus funciones. Como sabemos, la legitimidad está en la institución que la ostenta, pero es construida por el ojo del receptor de sus acciones, ${ }^{53}$ y ello obliga, a nosotros y a los tribunales cuando diseñan su identidad, a mirar las representaciones sociales vigentes sobre el rol judicial. Según sostiene Barak:

La creación judicial que conecta la brecha entre Derecho y sociedad debe ser coherente no sólo con los valores básicos de la sociedad, sino también con la fundamental percepción social del rol que tiene el Poder Judicial. El poder de un juez para conectar esas dimensiones en una sociedad que, como la de Montesquieu, ve al juez solamente como la boca que pronuncia las palabras de la ley es diferente al poder de un juez en una sociedad que ve la creación judicial de Derecho como legítima. La percepción social del rol judicial, de todas maneras, es fluida. La actividad judicial no sólo está influida por ella; también ésta influencia esa percepción. ${ }^{54}$

52 "Lo que genera el poder de las palabras y las palabras de orden, el poder de mantener el orden o de subvertirlo, es la creencia en la legitimidad de las palabras y de quien las pronuncia...". Bourdieu, Pierre, Derecho y clases sociales, Bilbao, Desclée de Brouwer, 2001, p. 98.

53 Por eso, Suchman va a sostener que "la legitimidad es una percepción o suposición en el sentido en que representa una reacción de los observadores a la organización como ellos la ven; por lo tanto, la legitimidad es poseída objetivamente, pero creada subjetivamente. La legitimidad es socialmente construida en el sentido de que refleja una coherencia entre las conductas de la entidad legitimada y las creencias compartidas (o presumiblemente compartidas) de algún grupo social". Suchman, Mark, op. cit., p. 574.

54 Barak, Aharon, op. cit., p. 33. 
Esto obliga a una prudente autoatribución de funciones por parte de los jueces, pues ellos deberán encarnar un sano activismo en pos de la protección de los derechos individuales, judicialmente consagrados, pero respetando los ámbitos de acción ejecutiva socialmente reconocidos. El juez está llamado a realizar una síntesis en los casos que se le someten a análisis, síntesis que deberá realizar a partir de la conciencia de una legitimidad compartida con otros poderes y un saber limitado. Su papel está caracterizado por una intervención en el proceso de toma de decisiones antes que por una monopolización a posteriori de la evaluación de las conductas. Las medidas cautelares, en este contexto, se muestran como instrumentos especialmente idóneos para cumplir las funciones que el juez adquiere contemporáneamente, pues se adaptan, por su carácter temporalmente transitorio y epistemológicamente tentativo, a la naturaleza experimental que tienen los procesos complejos de intervención jurídica. Asimismo, las medidas cautelares suelen ser utilizadas como una instancia en la que el proceso de ejecución se detiene y abre así una opción de diálogo en la esfera pública, el cual anteriormente - probablemente por la oscuridad del mismo procedimiento administrativo - no se habría producido. De este modo, es en la utilización de las medidas cautelares donde mejor pueden visualizarse los cambios de paradigma que hemos venido analizando a lo largo de este trabajo.

\section{EPÍlOGO}

Hablar de un nuevo paradigma puede resultar apabullante a la hora de tener que fundamentar tal afirmación y la consiguiente obligación de no dejar ningún cabo suelto. Nuestra intención a lo largo de estas páginas ha sido más modesta, limitándonos a proponer una lectura de los grandes cambios acaecidos en la función del juez y cómo ellas se concretan de manera eminente en la intervención cautelar. Nos hemos aproximado a esta idea desde las transformaciones de un derecho que cambia sus relaciones con la realidad social, juridizándola, al tiempo que modifica su estructura interna, constitucionalizándose. Este doble movimiento, externo e interno, confluye en una preeminencia de la garantía individual - jurídica - sobre las normas - políticas - de conducción y armonización social, llevando a una situación de pluralismo decisional donde los jueces asumen un rol central. Los jueces se transforman en guardianes de los derechos y garan- 
tías constitucionales, de los cuales tienen las llaves para su interpretación. Los jueces se encargan de dar cabida a estas transformaciones jurídicas, a la vez que legitiman su actuar a partir de ellas. Los derechos individuales plantean casos individuales que motivan su actuar, al tiempo que esos mismos derechos articulan una visión poderosa de su función. Ello se concreta claramente en la formulación de la "tutela judicial efectiva" como garantía individual que, al mismo tiempo, le permite al juez expandir sus poderes y, entre otras cuestiones, dictar medidas cautelares.

Es el cambio de función del derecho y su mayor grado de intervención en la conformación de la sociedad el que va producir las transformaciones en sus mecanismos de legitimación. Derecho y cambio social están hoy inextricablemente unidos, y el protagonismo del juez se juega en ese punto de encuentro. Así, el proceso cautelar se manifiesta como una instancia de diálogo público que viene a manifestar la pérdida del lugar monopólico que los órganos legislativos y administrativos tenían en la determinación del interés general. Entendiendo el derecho como un ámbito social discursivo en el que se definen las cuestiones esenciales de la vida comunitaria, la forma en que va a regirse, el proceso judicial es uno de los lugares en los que la articulación de la sociedad plural — algunos hablarán de fragmentación - podrá realizarse. Las medidas cautelares poseen una gran fuerza de intervención social al actuar en un tiempo judicial presente, y que mira al futuro antes que al pasado. Su capacidad, sin embargo, no es ilimitada, sino que depende de la legitimidad social que ostenten los magistrados que las ordenan, y ésta dependerá de su propia capacidad para articular una participación procesal amplia. El monopolio administrativo no se rompe de cuajo ni tampoco se traslada al juez in totum, pero sí encuentra un núcleo moderador, un freno efectivo que da espacio al pluralismo social. Esta perspectiva, entendemos, abre nuevas formas de pensar la intervención cautelar y nos libera de las tradicionales categorías del derecho administrativo.

\section{BIBLIOGRAFÍA}

Asociación por los Derechos Civiles (ADC), "Vamos a portarnos mal". Protesta social y libertad de expresión en América Latina, Buenos Aires, ADG-Friedich Ebert Stiftung, 2011.

AshforTh, Blake y GiBBS, Barrie W., "The Double-Edge of Organizational Legitimation”, Organization Science, vol. 1, núm. 2, 1990. 
BARAK, Aharon, "AJudge on Judging: The Role of a Supreme Court in a Democracy", Harvard Law Review, vol. 116, 2002.

BARrA, Rodolfo Carlos, Principios de derecho administrativo, Buenos Aires, Ábaco, 1980.

BASCH, Fernando, "Breve introducción al litigio de reforma estructural", documento base para el seminario "Remedios Judiciales y Monitoreo de Ejecución de Sentencias en el Litigio de Reforma Estructural", Facultad de Derecho de la Universidad de Buenos Aires, 4 y 5 de noviembre de 2010.

Berman, Marshall, Todo lo sólido se desvanece en el aire. La experiencia de la modernidad, Madrid, Siglo XXI Editores, 1988.

Bourdieu, Pierre, Derecho y clases sociales, Bilbao, Desclée de Brouwer, 2001.

Centro de Estudios Legales y Sociales, La lucha por el derecho. Litigio estratégico y derechos humanos, Buenos Aires, Siglo XXI Editores, 2008.

Chevallier, Jacques, "La dimension symbolique du principe de légalité", Revue du Droit Public, núm. 6, 1990.

COUlDRY, Nick, "Mediatization or Mediation? Alternative Understandings of the Emergent Space of Digital Storytelling", New Media $\mathcal{E}^{\circ}$ Society, núm. 10, 2008.

DE BúRCA, Gráinne y SCOTT, Joanne, "New Governance, Law and Constitutionalism", en DE BúRCA, Gráinne y SCOTT, Joanne (eds.), Law and New Governance in the EU And The US, Oxford-Portland, Hart Publishing, 2006.

Dorf, Michael C. y SABel, Charles F., "A Constitution of Democratic Experimentalism", Columbia Law Review, vol. 98, núm. 2, 1998.

ESKRIDGe, William N. y Ferejohn, John, "Constitutional Horticulture: Deliberation-Respecting Judicial Review", Texas Law Review, vol. 87, 2009.

FAVOREU, Louis, "La constitucionalización del derecho", Revista de Derecho, vol. XII, 2001.

FIORAVANTI, Maurizio, "Per un nuovo costituzionalismo", Democrazia e Diritto, núm. 1, 1997.

FRIEDMAN, Lawrence M., Ahora elijo yo. La república de las opciones infinitas, Buenos Aires, Grupo Editor Latinoamericano, 1992.

—, Total Fustice, Nueva York, Russell Sage Foundation, 1994.

FUlLER, Lon, "The Forms and Limits of Adjudication", Harvard Law Review, vol. 94, 1978. 
GARCía MORILlO, Joaquín, "El parlamento en la era global”, Cuadernos de Derecho Público, Madrid, núm. 1, 1997.

GRIMM, Dieter, "Integration by Constitution", I-CON International fournal of Constitutional Law, vol. 3, núms. 2 y 3, 2005.

Guarneri, Carlo y Pederzoli, Patrizia, Los jueces y la politica. Poder Fudicialy democracia, Madrid, Taurus, 1999.

Hamilton, Alexander et al., El Federalista, México, Fondo de Cultura Económica, 1994.

Hesse, Konrad, Escritos de derecho constitucional, Madrid, Centro de Estudios Constitucionales, 1983.

INGLEHART, Ronald, Modernización y posmodernización. El cambio cultural, económico y político en 43 sociedades, Madrid, CIS, 1998.

Kagan, Robert, Adversarial Legalism. The American Way of Law, Boston, Harvard University Press, 2003.

Koselleck, Reinhart, “¿Existe una aceleración de la historia?”, en BERIAIN, Josetxo y AGuiLuz, Maya (eds.), Las contradicciones culturales de la modernidad, Barcelona, Anthropos, 2007.

Liebman, James S. y Sabel, Charles F., "A Public Laboratory Dewew Barely Imagined: The Emerging Model of School Governance and Legal Reform", New York University Review of Law \& Social Change, vol. 28, 2003.

Montesquieu, Barón de, Del espiritu de las leyes, 2a. ed., trad. de Mercedes Blázquez y Pedro de Vega, Madrid, Tecnos, 1993.

Nonet, Philippe y Selznick, Philip, Law E Society in Transition: Toward Responsive Law, 2a. ed., Nueva York, Octagon Books, 2001.

Oтто, Ignacio de, Estudios sobre el Poder Fudicial, Madrid, Ministerio de Justicia, 1989.

Parejo Alfonso, Luciano, Crisis y renovación en el derecho público, Madrid, Centro de Estudios Constitucionales, 1991.

PORRAS NADALES, Antonio, Introducción a una teoría del Estado postsocial, Barcelona, PPU, 1989.

Preuss, Ulrich K., "The Conceptual Difficulties of Welfare Rights", en Sajo, A. (ed.), Western Rights? Post-Communist Application, Holanda, Kluwer Law International, 1996.

Pulitano, Domenico, "Supplenza giudizaria e poteri dello Stato", Quaderni Costituzionali, año 3, núm. 1, 1983. 
Rodríguez Garavito, César, "Beyond the Courtroom: The Impact of Judicial Activism on Socioeconomic Rights in Latin America", Texas Law Review, vol. 89, 2011.

RUBio LLORENTE, Francisco, "La jurisdicción constitucional como forma de creación de derecho", Revista Española de Derecho Constitucional, núm. 22, 1988.

Sabel, Charles F. y Simon, William H., "Destabilization Rights: How Public Law Litigation Succeeds", Harvard Law Review, vol. 117, 2004.

- y ZEITLIn, Jonathan, Experimentalist Governance in the European Union. Towards a New Architecture, Oxford, Oxford University Press, 2010.

- y SimOn, William H., "Minimalism and Experimentalism in the Administrative State", The Georgetown Law Fournal, vol. 100, 2011.

SARTORI, Giovanni, Ingeniería constitucional comparada, México, Fondo de Cultura Económica, 1994.

ScotT, Joanne y Sturm, Susan, "Courts as Catalysts: Re-Thinking the Judicial Role in New Governance", Columbia Fournal of European Law, vol. 13, 2006.

STRÖMBACK, Jesper, "Four Phases of Mediatization: An Analysis of the Mediatization of Politics", The International Fournal of Press/Politics, núm. 13, 2008.

Suchman, Mark, "Managing Legitimacy: Strategic and Institutional Approaches", The Academy of Management Review, vol. 20, núm. 3, 1995.

TARUFFO, Michele, "Note sui modi della giuridificazione", Politica del Diritto, año 18, núm. 4, 1987.

Thompson, John B., "The New Visibility", Theory, Culture Ë Society, vol. 22, núm. 6, 2005.

Thury CORnejo, Valentín, "Could Authenticity Fill the Gap?", Realidad, núms. 6-7, 2009.

—_, Juez y división de poderes hoy, Buenos Aires, 2002.

_- "La legitimidad de los tribunales supremos y sus estrategias comunicativas. El caso de la Corte Suprema de EE.UU.", Estudios Constitucionales, año 7, núm. 2, 2009.

Vega García, Pedro de, "Jurisdicción constitucional y crisis de la Constitución", Revista de Estudios Políticos, núm. 7, 1997.

Weber, Max, Economía y sociedad. Esbozo de sociología comprensiva, México, Fondo de Cultura Económica, 1979.

Zagrebelsky, Gustavo, El derecho dúctil. Ley, derechos, justicia, 2a. ed., Madrid, Trotta, 1997. 